\title{
An application and management system of smart city
}

\author{
Yong $\mathrm{Li}^{1,}$, , Yang $\mathrm{Li}^{2, \mathrm{a}}$ and Jie $\mathrm{Li}^{2, \mathrm{a}}$ \\ ${ }^{1}$ Beijing University of Technology, Beijing, China \\ ${ }^{2}$ Full 1DIGITAL CHINA(CHINA)LIMITED, Beijing, China \\ adigital9898@sina.com
}

Keywords: Smart city, data resource management, geocoding management, video monitoring

\begin{abstract}
Proposed a smart city management system, which can complete the basic data resource management, geocoding management, accept supervision, teamwork, supervision and management, comprehensive evaluation, video monitoring, application maintenance, wireless data collection, problem reporting, data exchange, mobile office and public information service platform, urban management portal and other functions, improve the efficiency of government departments.
\end{abstract}

\section{Introduction}

With the development of city construction, to improve the government's management capacity and service levels, to achieve efficient energy services, the use of IT to establish full-time, all-area coverage of smart city management system is an important part of city construction. Through the construction of smart city management system, build integrated management, unified command, intelligent decision-making, business collaboration, shared services platform for the integration of information, support daily management and decision-making at all levels of administration of the city, improve work efficiency.

In order to achieve urban sophisticated management, smart city management system using visual identification, wireless sensor, wireless location, RFID tags and other networking technology to build ubiquitous network environment, urban management unit for automatic acquisition and real-time monitoring and collection data visualization and standardized processing, realize real-time perception of city and event, visualize the integrated management of the city.

\section{System architecture}

The system function is divided into four layers: the interface layer, data layer, business layer and the platform layer. Interface layer realize the perception of terminal data acquisition and interface with other business systems function; the data layer is responsible for managing data related to urban management; business layer fulfill the system's core business functions, provide support for the platform layer; the platform layer implementation service interactions with outside system.

Smart city management system includes the following business functions: basic data resource management, geocoding management, urban component updates, accept supervision, teamwork, supervision and command and management, comprehensive evaluation, video monitoring, application maintenance, wireless data collection, problem reporting, data exchange, mobile office and public information service platform, urban management portal. The logic architecture of management system is shown in Figure 1.

Smart city management system mainly used by city managers and policy makers. Based on city management system, government can make decision, timely forecasts and respond to emergencies and natural disasters, so improve the government's ability to govern. The systems can be used by specific personnel and business sectors, including city management supervision and law enforcement personnel, dealing with urban emergency dispatch center, city managers and departments at all levels of an integrated urban management as well as the majority of enterprises and the public. 

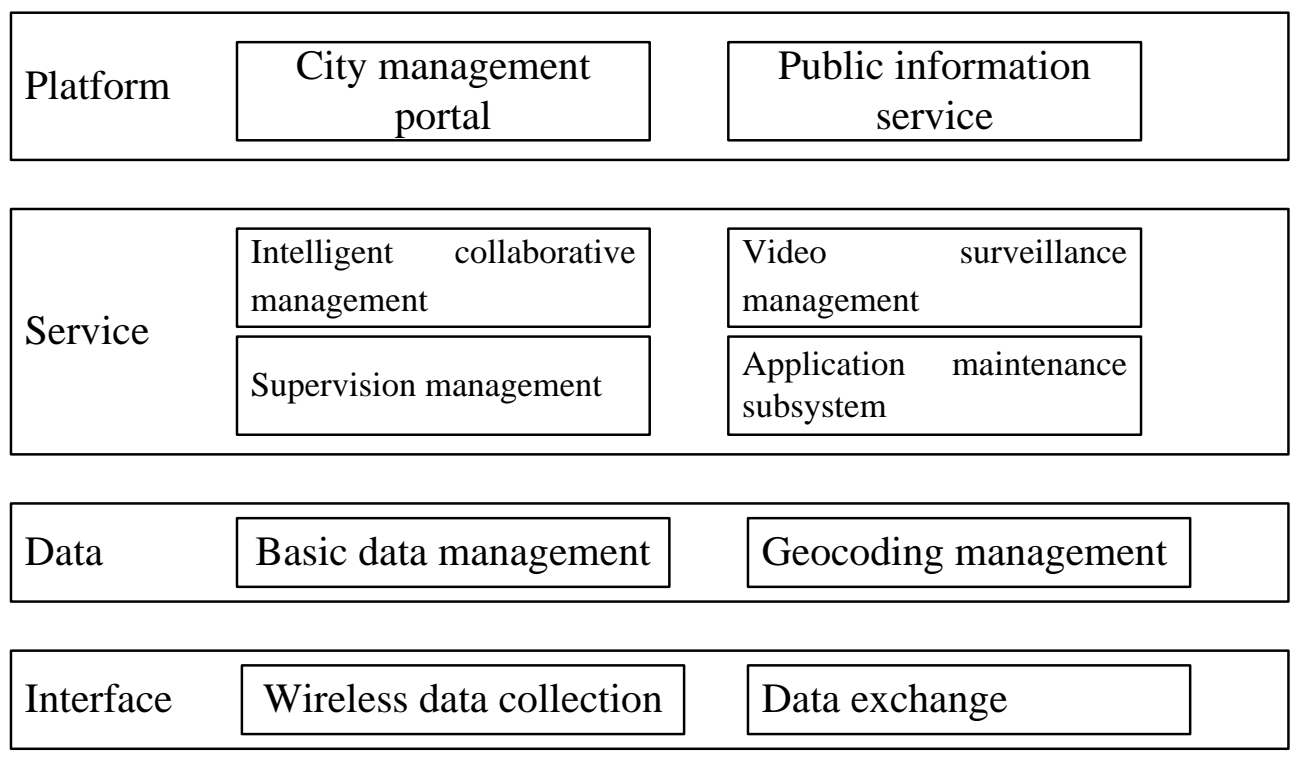

Fig.1 system architecture of management system

External interface function of smart city management system implemented by wireless data acquisition, urban component updates and data exchange. Wireless data acquisition and city updates, to achieve the perception of urban management in a variety of interactive information terminals. Data exchange realized the wisdom of urban management system has interfaces to other systems interact with business and data requirements, including other related business systems such as intelligent transportation systems, the wisdom of the medical system, smart grid and safe cities.

\section{Basic data management system}

Basic data management system is used by system administrators. Basic database management system maintain the library, also be the basis of data sources used in the system management; tools provided by the system, the system administrator can define a layer, expand map data, use the feature definition, adapt to changes in standards.

The main function of the underlying data management map data management, map editing, spatial statistics, spatial analysis and so on.

\section{Geocoding management}

Geocoding is one of the important parts in grid city management, through the use of geocoding technology and spatial database technology. Geocoding service can connect resources information with geographic coordinates, to help effective analysis and decision-making applications. Through the semantic analysis of natural language address information, lexical analysis, and automatically matches the standard address database, the system can determine the precise geographic coordinates. The main functions of geocoding management including geocoding management, address description, address lookup, and address matching.

\section{Regulatory issues management}

In the smart city management systems, focus concerns into two categories: public report, supervisors report. Through supervision and management system, receive problems from inspectors and the public urban, and then record problem, management control and supervision passed to the city center after the filing.

Regulatory issues management include event registration, event location, the supervisor on-site verification, filing and docket approval, the results of feedback and verification, closed archive management, docket rollback files inquiries, process monitoring and other files.

\section{Intelligent collaborative management system}

Intelligent collaborative management system mainly used by city management control and supervision center, professional office staff departments. Office staff enters the system through the browser management collaborative work platform. The contents of different users can be controlled according to the permissions right. 
Intelligent collaborative management system can achieve urban city management office automation, graphics, text, tables, and business management integration; achieve interoperability between the control and supervision of the central city management, collaborative working platform workflow based on the professional sector.

Smart management can supervise the task of professional sector, and sends the audit results to the relevant professional departments; send reminders notice to delayed cases.

\section{Supervision and command information management}

Supervision and command information management can achieve real-time monitoring, ease control and supervision of the city center. Cities managers can intuitively grasp events in each region by monitoring the big screen TV or monitor information, business process information, and other information can also be queried on the circumstances of each grid, supervisors, members and other individuals.

Main features include files inquiries, files back, send and receive files management, reports, statistics, evaluation queries, GIS interactive diagram number, large-screen display.

GIS can load and display spatial data and urban basic components, event data; with window zoom, roaming, full map, select other basic graphics operations functions; able to locate based on components, event information, and monitors information in the diagram and tracking.

Large screen display function is realized through the big screen controller, will be specified machine interface displayed on the big screen, other staff members can intuitively grasp the information of each area in the city on the big screen, event handling information, docket information, evaluate the information and other global situation; can also check on the situation in each area, information collection staff, members and other individuals.

\section{Video surveillance management}

Video surveillance management can display video monitor signal on the big screen TV, realize full-time visual monitoring and management, so a comprehensive city management to make accurate judgments and timely response to emergencies within the monitoring range of video evidence, and have a comprehensive treatment effect.

The main features include video capture, video compression and decompression, the video image storage, video playback, video data is transmitted, the received video data, the video ID and location, the video source selection, control and adjustment of the monitoring probe.

\section{Application maintenance subsystem}

Application maintenance subsystem is used by system administrators, the platform can quickly build and maintain city management services, customized business workflow, set up the organization, and be able to complete the work quickly and easily adjust the style form content, business process changes, personnel changes and other routine maintenance work permission. System administrators can easily adjust the system to fit the changing needs by application maintenance subsystem.

Key features include performance monitoring, user management, organization management, fault recovery, data backup and restore, system monitoring and management.

\section{Wireless data collection}

Wireless data collection used by city management supervisor to collect and transmit information rapidly. City management supervisor use the appropriate function of the information collection, inspects in the divided region and submit related information to the city's city event management control and supervise center, while receiving job dispatch and scheduling management command, and supervision of the city center. Wireless data acquisition system connected to a wireless data acquisition system, transmit various data via a proprietary wireless transmission network or public wireless transmission network, and realize site location positioning, messaging, voice calls and other functions.

\section{Data exchange}

Data exchange realize information transfer and exchange between different level of city management systems, and smart city management systems and other service systems, exchange information including the issue of information, business process information, and comprehensive evaluation information. 
Data exchange adopt a mature IT industry to establish an information exchange platform, including data exchange engine, remote data transmission, information exchange standards and other core modules.

\section{Mobile OA}

In order to ensure key and difficult issues in city management, timeout handling problems can be resolved promptly and effectively, while facilitating city managers, ready to work, attention of city management situation, the system provides the city manager mobile office function.

\section{Public information service platform}

Public information service platform, including government portal system, LED outdoor big-screen information dissemination. Enables online reporting, digital city management system, information publicity, complaints and evaluation, case processing satisfaction surveys, integrated information query, online consulting, government affairs, social services, business services, web forums, information dissemination and other sites display terminal applications. The system capable of user permission settings; allow administrators to manage the site in the column to increase the column plates; able to publish articles and website management style; also can monitor the site and restore function.

\section{Smart City Management Portal}

Smart City Management Portal provides personalized demonstrate ability to different roles, provides personalized interface customization for each participating city management roles, interfaces show function. City management portal can show the city related data information to the city manager directly, imagery and dynamically.

\section{Summary}

Proposed a smart city management system, which will help management anticipate and respond to emergencies timely, thereby improving the government's ability. After connected with other relevant service systems related to intelligent transportation systems and urban management, the wisdom of the medical system, smart grid, safe cities and other information exchange, promote city information level.

\section{Acknowledgements}

This work was financially supported by the project 2012AA01A403.

\section{References}

[1] Mulligan, C.E.A.; Olsson, M. Architectural implications of smart city business models: an evolutionary perspective, Communications Magazine, IEEE, Volume: 51, Issue: 6, 2013, Page(s): 80 $-85$

[2] Sanchez, L.; Gutierrez,V.;SmartSantander: Experimentation and service provision in the smart city , Wireless Personal Multimedia Communications (WPMC), 2013 16th International Symposium on, 2013, Page(s): $1-6$

[3] Menniti, D.; Sorrentino, N.In the future Smart Cities: Coordination of micro Smart Grids in a Virtual Energy District, Power Electronics, Electrical Drives, Automation and Motion (SPEEDAM), 2014 International Symposium on, 2014, Page(s): 676 - 682

[4] Zanella, A.; Bui, N. ; Internet of Things for Smart Cities, Internet of Things Journal, IEEE, 2014, Page(s): $22-32$

[5] Shi Lu, The Smart City's systematic application and implementation in China, Business Management and Electronic Information (BMEI), 2011 International Conference on, 2011, Page(s): $116-120$ 
[6] Balakrishna, C., Enabling Technologies for Smart City Services and Applications, Next Generation Mobile Applications, Services and Technologies (NGMAST), 2012 6th International Conference on, 2012 , Page(s): 223 - 227 